\title{
Study on the Inheritance Value of the Folk Songs in Hainan Miao Nationality
}

\author{
Huaming Cai \\ Art College, QiongZhou University, Sanya, 572022, China
}

Keywords: Folk songs in Miao Nationality, Inheritance, Value, Social function

\begin{abstract}
In this paper, elaborating from the historical culture and art features of the folk songs in Hainan Miao Nationality, it hopes to find a breakthrough in its tradition methods and value studies from the perspective of researching the excavation, conservation and inheritance of the folk songs in Hainan Miao Nationality. It aims at refining the historical evolution direction and cultural and academic ideas of Hainan folk songs, restoring and reconstructing the cultural diversity and historical cultural inheritance, and strengthening the protection on the inheritance of Hainan Miao folk songs.
\end{abstract}

\section{Introduction}

Hainan Miao nationality is one of the minorities with a long history in China, and its folk songs have unique art personalities and social functions. We place the folk songs in Hainan Miao nationality into the ethnic and cultural background for textual research, and explain the relationship of the mutual achievement between art and environment, which contributes to better protect and inherit those very precious folk songs in Hainan Miao nationality.

\section{Inheritance Value of Folk Songs in Hainan Miao Nationality from a Historical Perspective}

\section{Historical background of the Inheritance of Folk Songs in Hainan Miao Nationality}

For the history of ethnic origin, mostly according to the records in the History of the Later Han Dynasty · West Miao Nationality Biography, the researchers of Miao ethnic origin think that the start of forming the Miao and Li tribes is the Hehuang Miao ancestor slave Yuan Jian escapes from Qin in the Dynasty of Qin Ligong in the Late Spring and Autumn Period, and it has thousands of years' history since the migration from Qin and Han Dynasty to the Upper Minjiang River. ${ }^{[1]}$ The culture of Miao Nationality in ancient Chinese culture is well known as its folk-custom characteristics. Confined by the acceleration of the fusion of modern and contemporary Han and Miao nationality, the cultural structure of pluralism complex Miao nationality has basically formed. The texture diversity of the origin of Miao nationality creates its unique language system and cultural representation, manifested in the three languages of Miao people, Han people and the integration and Miao and Han, and in the cultural system. The descendants of Miao people speak Miao language and follow the traditions of Miao nationality; while the descendants of Han people speak Chinese and follow the traditions of both Miao nationality and Han nationality. Based on this, the folk songs of Hainan Yazhou Miao nationality both has geographical and cultural derivation traits, and has the beauty of historical inheritance. Despite the lack of the implementation of historical text describing in the level of text, the original folk song taught by oral instruction and rote memory becomes an importance reference of its national Psychological formation, memory changes and historical and cultural transformation. The inheritance of folk songs creatively gives play to music. On the one hand, preserve the original cultural relics by compiling the tune of the folk songs in Miao nationality in the form of oral literature to. In the protection process, in the form of field research, the famous linguist Tian Xintao et al cumulatively visit a few months and years and physically record the richest firsthand materials, which have a strong historical significance and research value. ${ }^{[2]}$ On the other hand, with the death of elder and sage who can completely chant and sing the folk songs, the folk songs are inherited by Chinese description and the younger generation acquisition. The compilation of Folk songs "three integrated" series in the region of Miao nationality started from the 1980s. ${ }^{[3]}$ The 
historical colloquial book based on this practice presents an original ecological form, and demonstrates the ethic characteristics of Hainan Miao nationality.

\section{Cultural Ideas of the Inheritance of Folk Songs in Miao Nationality}

The above practice has provided a cultural basis of "thick description" and analysis for us to explore the cultural context of folk songs in Miao nationality. Examining the historical context of the folk songs' origin, the thick description and shallow description ideas proposed by Clifford Geertz in the Explanation of Culture have more anthropological interpretations and reference meanings. ${ }^{[3]}$ In his view, the thick description is to describe the network spot in the meaning network, and explain other spots using this network through connecting the spots into a network and expanding the meaning network. If cannot combine the cultural nature to explain, it will reconstruct the objects of cultural thick description. Our explanation on the cultural diversity of the folk songs in Hainan Miao nationality, and the interpretation on the hybridity meaning and cultural connotation of folk song culture are inevitably based on the basic idea of thick description. The representation of Miao culture is the generation mode about existence and symbolic meaning handed down in history, the art symbols of folk songs are located in the above conceptual system of interaction before and after, as well as the passage of contexts, and their inheritance of life cognition and attitude are realized in the form of music. In other words, the interpretation of cultural history of folk songs in Miao nationality is to shape a kind of explainable text, and to seek a cultural structure to explain science. Just as the British scholar Danica Los Guevara said, the explanation of culture is to explain its system of cultural symbols. ${ }^{[4]}$ Although there are cultural symbols of folk songs do not give us so many clues to our explanation, we use the music system and the basic characteristics of folk songs are able to break the cultural practices and social rules behind the symbolic system. From the cultural development process, the restore of the folk songs' history in Miao nationality can be a concrete image, and the memory of folk songs' history can be introduced into the practice, and the existed history of folk song events can be perfected by historical memories. However, restricted by the missing of spoken and written language, the records form historical documents are relatively defective, so the guiding significance of history restore has stood out for re-examining the historical ecology and cultural develop of folk songs in Hainan Miao nationality. Of course, the memory does not mean history, and cannot be copied. The historical thick description inevitably has its limitations for the consideration of memory reliability. The thick descriptions of social order reshape and the legitimacy of political order in Miao nationality has a correct meaning. Restoring the historical records of folk songs in Hainan Yazhou and reconstructing the cultural diversity of Miao nationality and its basic context of inheritance has laid a foundation for its cultural studies.

\section{Inheritance Value of Folk Songs in Hainan Miao Nationality from a Cultural Perspective}

\section{Inheritance Content of Folk Songs in Hainan Miao Nationality}

In the Western Musicology Domain, conceptual fuzziness exists in the Ethnomusicology. The Ethnomusicology is more concerned about synchronic concept of music, rather than diachronic discussion. Studying the historical ethnic music, "if some historian cannot see any conclusive things from the materials, it is because he does not go to seek, rather than there is not inside" [5] . As a result, the path of historical level of ethnomusicology not only needs to put music into historical background to conduct historical research, but also needs to take the art works as the explanation of transformational content, so that to explain the mutual generation and realization of art and environment. Based on this, the public inheritance of Miao nationality takes the basic form of "using songs to replace texts", and it uses songs to express national events, cultural contents, thereby allowing the future generations to inherit and carry forward its outstanding qualities. The lyrics of such folk songs are relatively simple, which are mostly self-improvise of singers, and there are unique cultural values between basic categories such as dancing songs, mountain songs, working songs, and drinking songs, etc.

Improve the basic ideas of singing and dancing music and harvest festivals 
From the county records of Hainan Miao nationality, it singing and dancing music (festive and funeral singing and dancing) is inherited from the folk songs in the Northern and Southern Dynasties. Festive music is used in the celebration, marriage and festivals, whose number of performers is not fixed, dividing men and women into one group. After the end of one song, it will change another song, and the atmosphere is more active, lively and enthusiastic. ${ }^{[3]}$ The folk songs in Hainan Miao nationality are inseparable from dances, the content of singing and dancing music inherited till now has a slight difference, and the basic form of dances similar. For the musical arrangement, it is composed by two musical phrases: head phrase or tail phrase. Its melody is more melodious, its tone is relatively high-pitched, and its rhythm tends to be gentle, so when singing, it adopts the pentatonic form, reflecting the natural and personal mood and emotional expression. It is mainly boys' duetto or duet between boys and girls, and through many nonsense syllables to form the passage structure, expressing the free, happy and relaxed mood of Miao nationality. In the particular inheritance process, it needs to specify the above basic ideas.

Keep the fixed singing pattern of working songs

The inheritance of folk songs is a kind of identification for the national cultural deposits, national history and folk culture. ${ }^{[6]}$ In terms of the folk songs in Hainan Yazhou, there are Li nationality, Miao nationality and Han nationality, while the working songs based on the Miao language are using historical forms to convey the everlasting labor emotions. Conforming to the rhythm in the working process, the working songs also play the ancient patterns of alternative duet. Be similar to the basic modes in history, the working song duet needs the cantor to be responsible for the high part, and other people are responsible for the low part, forming an alternative troll mode. While the basic libretto adopts nonsense syllables or a fixed set of words, the basic melody structure adopts double-sentence structure, the sense of rhythm and melody is relatively prominent, and the ethnic colors are rich. The melody of the working songs is complete, natural and fast-paced, and often has some fixed sets of words "Na Deng Qiao”, which is a relatively fixed and stylized basic mode formed after the historical baptism.

\section{Strengthen the appeal of daily drinking songs in Miao nationality}

When discussing the folk society in Hainan Miao nationality, we emphasize the importance of historical memory, and fully pay attention to the record-nature research methods of folk music when collecting the specific folk music. For example, the drinking song is the ancient singing way in the drinking occasions of weddings and funerals, which has high-pitched tones, four degree melody, five degree jump and wide rhythm. It often adopts vibrato, rich timbre and changeable rise and fall, showing a strong appeal and expressive force by interleaving and scattered music forms. When we go deep into the corridor area of Li nationality and Miao nationality of Miao village, we find that the content of drinking songs till now is to sing the impromptu songs on the spot. Drinking songs appear in the folk occasions, and produce a plaintive effect on the basis of chant.

\section{Shape and Structural Characteristics for the Inheritance of Folk Songs in Hainan Miao Nationality}

On the one hand, the singing forms of folk songs in Hainan Miao nationality are historical and quaint, and mostly use relatively fixed organizational structure, quartet with some tones or chorus. Based on this, the inheritance of folk songs in Miao nationality needs to emphasize the integration of itself and the inheritance of shape and structural characteristics. Even it more adopts the duet of boy and girl or the antiphonal singing form, and the level of sound mixing is also common. This singing way is determined by the basic factors on its social significance, for example, on the combination ways of labor, the multi-voice folk songs are related to the specific labor practice, which the differences in the characteristics of gender and the differences in the division of labor are largely contributed to the evolution of combination ways. The complexity and backwardness on the environment of Miao people since ancient times also determine that Miao people inevitably use collective labor to achieve good expressions of their singing content. In addition, the human geographical characteristics of Miao people to some extent are contributed to the specific gamut of Miao people. If we can adopt mixing singing mode, it must be able to form a gap separation effect, and to achieve the final combination of tones by mutual coordinated duet. 
On the other hand, the inheritance of singing shape and structure of folk songs in Hainan Miao nationality needs to pay attention to flexibility and diversity choosing. The multi-voice folk songs in Hainan Miao Nationality are not fixed on the scale of chorus, whose high part is completed by a lead singer and other parts are undertook by the rest of the participants. The singing speed mostly adopts the gradually intermediate speed mode, neutral tons and shaking voice singing. Such kind of singing skill is from the rise and fall of tones and the timbre traits of Miao language. The voice part of singing has a longitudinal dimension, and in the specific structure of voice part, it often uses the basic part of lead singing and chorus. The two parts horizontally represent to be same words and same rhythm, and longitudinally are the combination of pitch intervals in the second degree and third degree. All in all, its diationic scale of folk songs' five voice nature is mostly used, and the use frequency of Qiaojue and Biangong is relatively high, while other retouching and modulation are the existence of partial voice, and the folk song mode is basically the same as the historical music mode.

\section{Cultural Significance for the Inheritance of Folk Songs in Hainan Miao Nationality from a Cultural Perspective}

\section{Strengthen the Value of Faith Identity of Miao Nationality and Ethnic Positioning}

As everyone knows, the way of cultural inheritance contributes to the excavation of national identity and national cultural values, and the folk songs in Hainan are rooted in the ancient religious beliefs of Miao nationality, which is also clear for the significance of the ethnic positioning of Miao nationality. Religious beliefs are based on the pre-classification of things, which divide the world into known universe and unknown universe - sacred and secular thing. Religious beliefs express the relationship between sacred things and secular things. The god cognition of Miao nationality is reflected in the level of their worshiped gods and ritual norms. As the code of communicating with gods, the folk song stipulates the behavior rules of the mankind to sacred objects. The worship services believed by the folk in Miao nationality are related to the god things, personal things and ghost things. As an important component of folk beliefs, singing book runs through the whole process of worship, Xiang Xie and Buddhist activities. ${ }^{[7]}$ Lacking of the content of singing book will make the whole Buddhist rituals lose cultural connotations and the essence of beliefs. The singing book has an impact on the society of Miao nationality through its spirit of national culture. The folk songs in Miao nationality have a strong local color and cultural details, which not only will bring the sense of identity for the cultural inheritance of Miao nationality, but also unite the common faith of the nation through art forms. For the interpretation of various religious occasions, it provides a strong system structure of religious beliefs for the gods and sacrifice of Miao nationality in the great space. The basic gods of folk songs in Miao nationality are able to bear the sacred mission of worship things for the national groups.

Improved the Level of Moral Education and Cognitional Education in Miao Nationality

As an important factor of cultural development and inheritance in Miao nationality, the folk songs in Hainan Miao nationality complete the value extraction of behavior codes in Miao nationality through behavioral patterns, reflecting the basic moral standards. The folk songs are filled with surviving skills and all kinds of cultural knowledge, which are available for many occasions such as working site, celebrations, and religious ceremonies. Through the inheritance of folk songs, the culture of Miao nationality can be mastered by more young people, achieving the transmission efficacy of cultural knowledge and national traditions. Such subliminal inheritance is more flexible than education, which contributes to the meaning of historical national moral norms on guiding the positive level of words and deeds in Miao nationality. In addition, the folk songs in Hainan Miao nationality contain the aesthetic standards of Miao nationality itself and its unique aesthetic mind. The basic spiritual value has been shown in the process of singing the folk songs in Miao nationality, which shows the connotations and aesthetic perception in the natures of Miao nationality, transmits the simple national aesthetic ideas, makes the public's minds can be communicated, and obtains the joy and comfort related to the appreciation and creation of folk songs. The folk songs also show the 
nature of entertainment, make the public of Miao nationality experience the force of music in working, and let their lives more abundant and colorful.

\section{Conclusion}

To sum up, this paper studies the inheritance value of the folk songs in Hainan Miao nationality from art, culture and history, explores the comprehensiveness of folk songs in Hainan Miao nationality and the inheritance of kindred nature of folk music in Miao nationality, which is convenient for perfecting the integration of folk music and culture, revealing the basic rules and unique system of folk songs, and based on the reference of cultural anthropology, it strengthens the similarities and differences of folk song researcher, and shows the unique personality and social functions of folk songs in Hainan Miao nationality on the original form.

\section{Acknowledgments}

This paper is one of the periodical achievements for the scientific research project "Study and Protection on the Immigrant Cultural Forms in the Ballads of Hainan Li Nationality", which founded by Hainan Provincial Department of Education. Project Number is 2014-68.

\section{References}

[1] ISBN Center. Collections of Chinese Folk Songs · Hainan. Beijing: ISBN Center, 2013

[2] Fu Guihua. 3000 Traditional Li Folk Songs. Haikou: Hainan Press, 2014

[3] Encyclopedia of China - Music and Dance. Beijing: Encyclopedia of China Publishing House, 2013

[4] Lu Feng. The Future of Modern Social Development and Activities. Journal of Chengdu Music Institute. 2011 (05): 12-15

[5] Bao Mingxiao. Study on the Basic Features of Our Social Music in the Primary Stage of Socialism. Collections of the Soft Scientific Research Achievements in Music 1999-2000. Compiled by the Department of Policies and Laws in the State Physical Culture Administration. 2011

[6] Yuan Yong, Wang Li. Explore the Inheritance and the Transmission of National aspirations in Hainan Local Music. Journal of West Anhui University. 2012(05): 34-36 